\title{
Viabilidade jurídica acerca da ampliação da licença maternidade
}

\author{
Legal feasibility regardling the extension of maternity leave \\ Viabilidad legal de la ampliación de la baja por maternidad
}

Recebido: 02/05/2021 | Revisado: 09/05/2021 | Aceito: 11/05/2021 | Publicado: 29/05/2021

\author{
Gilmara Dias Galvão Carmizini \\ ORCID: https://orcid.org/0000-0003-2609-6015 \\ Faculdade Assis Gurgacz, Brasil \\ E-mail: gilmaradg@gmail.com \\ Raquel Lauriano Rodrigues Fink \\ ORCID: https://orcid.org/0000-0002-0245-6349 \\ Faculdade Assis Gurgacz, Brasil \\ E-mail: raquellauriano@hotmail.com
}

\begin{abstract}
Resumo
A licença maternidade é um direito da mãe, dessa forma o Estado deve garanti-lo. Não obstante a existência de leis que desempenham a proteção à amamentação ocupando papel fundamental, o cenário jurídico atual leva à uma reflexão referente ao período de licença, mormente diante da previsão legal de afastamento de 120 dias, havendo uma discrepância com a necessidade da criança em relação à amamentação, de mínimo de 6 meses de amamentação exclusiva, como defendem a Organização Mundial da Saúde e o Ministério da Saúde. O trabalho visou analisar a viabilidade da expansão da licença maternidade propondo sua ampliação para, no mínimo, 180 dias, em contraposição ao previsto na legislação brasileira. Abordou a legislação interna, a exemplo da Lei n ${ }^{\circ} 11.770 / 08$ que criou o Programa Empresa Cidadã, a qual faculta às empresas sua adesão para ampliação da licença para 180 dias como forma de incentivo fiscal, o que, no entanto, implica em tratamento desigual entre as trabalhadoras. Comparando as legislações nacionais e internacionais vigentes acerca da licença maternidade pode-se perceber que há outros países que preveem maiores benefícios às mães com períodos maiores de licença maternidade. Para elaboração do presente estudo foi realizada uma pesquisa bibliográfica em textos legais, doutrina e artigos científicos. Como conclusão, respeitando os princípios constitucionais, voltados aos direitos e garantias individuais do ser humano, verifica-se viável e necessária a ampliação do período da licença maternidade, visando a proteção de direitos fundamentais e melhores condições de vida pessoal e profissional da mãe e, por consequência, de seu filho.
\end{abstract}

Palavras-chave: Licença maternidade; Viabilidade da expansão; Organização Mundial da Saúde; Programa empresa cidadã; Desigualdade.

\begin{abstract}
Maternity leave is a mother's right; therefore, the State must guarantee it. Notwithstanding the existence of laws that protect breastfeeding, playing a fundamental role, the current legal scenario leads to a reflection regarding the period of leave, especially in view of the legal provision of 120 days leave, with a discrepancy with the child's need in relation to breastfeeding, for a minimum of 6 months of exclusive breastfeeding, as advocated by the World Health Organization and the Ministry of Health. The work aimed to analyze the feasibility of expanding maternity leave by proposing its expansion to at least 180 days, in contrast to what is provided for in Brazilian legislation. It approached the internal legislation, such as Law $n^{\circ} 11.770 / 08$, which created the Citizen Company Program, which allows companies to sign up to extend the leave to 180 days as a form of tax incentive, which, however, implies unequal treatment among female workers. Comparing the current national and international laws regarding maternity leave, it can be seen that there are other countries that provide greater benefits to mothers with longer periods of maternity leave. To prepare the present study, a bibliographic search was carried out in legal texts, doctrine and scientific articles. As a conclusion, respecting the constitutional principles, focused on the individual rights and guarantees of the human being, it is feasible and necessary to extend the period of maternity leave, aiming at the protection of fundamental rights and better personal and professional life conditions for the mother and, consequently, for her child. Keywords: Maternity leave; Expansion feasibility; World Health Organization; Citizen company program; Inequality.
\end{abstract}

\section{Resumen}

La baja por maternidad es un derecho de la madre, por lo que el Estado debe garantizarla. A pesar de la existencia de leyes que protegen la lactancia materna jugando un papel fundamental, el escenario legal actual conduce a una reflexión 
sobre el período de licencia, especialmente ante la disposición legal de 120 días de licencia, con una discrepancia con la necesidad del niño en relación a lactancia materna, de un mínimo de 6 meses de lactancia materna exclusiva, como sostienen la Organización Mundial de la Salud y el Ministerio de Salud. El trabajo tuvo como objetivo analizar la viabilidad de ampliar la licencia por maternidad proponiendo su ampliación a, al menos, 180 días, en contraste con las disposiciones de la legislación brasileña. Se acercó a la legislación interna, como la Ley $\mathrm{n}^{\circ}$ 11.770/08, que creó el Programa Empresa Ciudadana, lo que permite que las empresas se suscriban para extender su licencia a 180 días como una forma de incentivo fiscal, lo que, sin embargo, implica un trato desigual entre las. Comparando las leyes nacionales e internacionales vigentes sobre la licencia por maternidad, se puede observar que hay otros países que brindan mayores beneficios a las madres con períodos más largos de licencia por maternidad. Para la elaboración del presente estudio se realizó una investigación bibliográfica sobre textos legales, doctrina y artículos científicos. Como conclusión, respetando los principios constitucionales, con el enfoque en los derechos y garantías individuales del ser humano, es viable y necesario extender el período de la baja por maternidad, objetivando la protección de los derechos fundamentales y mejores condiciones de la vida personal y profesional de la madre y, en consecuencia, tu hijo.

Keywords: Licencia por maternidad; Viabilidad de la expansión; Organización Mundial de la Salud; Programa de empresa ciudadana; Desigualdad.

\section{Introdução}

No decorrer da história ocorreram mudanças relativas aos direitos sociais, o que inclui algumas garantias específicas para as mulheres, visando a preservação e manutenção de seu trabalho, notadamente, a conquista da licença maternidade, sendo o objeto do estudo deste trabalho o período da licença maternidade.

Nos termos do artigo $7^{\circ}$, inciso XVIII da Constituição Federal e do artigo 392 da CLT, a licença maternidade é um direito da mãe que lhe garante um afastamento de 120 dias de suas atividades laborais, sem prejuízo do emprego e do salário.

O tema está direcionado, primeiramente, ao Direito do Trabalho que, de acordo com Martins (2019), "é o conjunto de princípios, inerentes à relação de trabalho, objetivando propiciar melhores condições de trabalho, de acordo com as medidas de proteção disponibilizadas ao trabalhador".

De acordo com a Organização Mundial da Saúde e o Ministério da Saúde (2009), a mãe deve amamentar o bebê por no mínimo seis meses. Com a amamentação a criança tem um melhor desenvolvimento, pois

É importante para o bebê ser aleitado com leite materno, desde a primeira hora de vida, trazendo muitos benefícios, como: redução da mortalidade infantil, melhor nutrição, redução de doenças infantis, melhor desenvolvimento neurológico, melhor qualidade de vida, promoção de vínculo afetivo entre mãe e filho, desenvolvimento dos órgãos fono-articulatórios, desenvolvimento do sistema estomatognático. (TJDFT, 2016, [s.p.])

Porém, como já exposto, o período de licença maternidade, conforme a legislação brasileira, nos artigos $7^{\circ}$, inciso XVIII da Constituição Federal e 392 da CLT é de apenas 120 dias. Neste sentido, importa a reflexão sobre o que a lei determina e o que a Organização Mundial da Saúde (OMS) recomenda (amamentação exclusiva até os 6 meses de vida do filho), comparandoas. Da análise, fica evidente que a lei estabelece 60 dias a menos do que o recomendado pela Organização Mundial da Saúde ficando, assim, impossibilitada a amamentação da criança, de forma exclusiva, com o leite materno. Neste sentido, faz-se necessário questionar se a licença maternidade, na forma como prevista atualmente em nosso ordenamento jurídico, atende às demandas da mãe e do filho, bem como aos princípios constitucionais e se há respaldo jurídico para a ampliação do período fixado em lei da licença maternidade.

O estudo é relevante à medida em que defende e analisa a viabilidade da ampliação da licença maternidade, sob o prisma dos princípios constitucionais, como o princípio da dignidade da pessoa humana e o da isonomia, visto que, para a mãe que trabalha fora de casa, retornar precocemente ao trabalho impacta tanto sua vida pessoal quanto profissional, além da saúde de seu filho, acarretando descontentamento e desconforto. 


\section{Metodologia}

Para elaboração do presente estudo foi realizada uma pesquisa bibliográfica em textos legais, doutrina e outros documentos que foram úteis para a abordagem do tema proposto. Portanto, a pesquisa bibliográfica insere-se na documental e está relacionada à linha de pesquisa "Atividade empresarial, novos desafios nas relações de trabalho" do grupo de pesquisa "Jurisdição, Mercados e Fronteiras" da Instituição de Ensino Superior de vinculação das autoras. O método para o desenvolvimento será teórico e, para o delineamento das conclusões, empregou-se a síntese do pesquisado, de forma a embasar a tese enunciada no objetivo geral do trabalho.

\section{Direitos e Garantias Fundamentais}

Desde o século passado diversas mudanças ocorreram na relação entre a mulher e o trabalho. Em um passado recente eram exploradas, havendo discriminação, diferença salarial e nas tarefas atribuídas em relação aos homens. No período Feudal houve importantes transformações no âmbito do trabalho, acabando a escravidão, porém, não ocorrendo grandes mudanças para a mulher, visto que "Quando admitida para trabalhar, jamais chegava a uma posição de destaque, sendo considerada a vida inteira como aprendiz, quer nas oficinas de corporação, quer no lar pelo marido.” (Figueredo, 2009, p.12)

Além disso, segundo Nascimento (2009, p. 727), "a mulher não é dotada da mesma resistência física do homem e a sua constituição é mais frágil, de modo a exigir do direito uma atitude diferente e mais compatível com seu estado".

Com a Revolução Industrial foram conquistados direitos sociais, agregando-se à proteção dos direitos e garantias fundamentais do indivíduo, o que torna relevante a análise dos princípios constitucionais garantidores desses direitos que são atrelados ao tema proposto. Ademais, destacar os impactos que a maternidade traz no âmbito do trabalho.

O direito ao trabalho é um direito fundamental declarado em nosso ordenamento jurídico, protegido pela Constituição Federal. Segundo Leite (2019, p. 41), "toda a pessoa tem direito ao trabalho, à livre escolha, a condições equitativas e satisfatórias de trabalho e à proteção contra o desemprego".

Ainda, complementando o que são direitos fundamentais,

(...) direitos fundamentais são direitos do homem, jurídico-institucionalmente garantidos e limitados espaçotemporalmente. Os direitos do homem arrancariam da própria natureza humana e daí o seu caráter inviolável, intemporal e universal; os direitos fundamentais seriam os direitos objectivamente vigentes numa ordem jurídica concreta. (Canotilho, 2003, p. 393).

Leite (2019) ainda cita exemplos, como princípio fundamental, conforme consta no artigo $1^{\circ}$, incisos II, III, e IV da Constituição Federal como direito social declarado nos artigos $6^{\circ}$ e $7^{\circ}$, bem como valor fundamental da ordem econômica, que tem por objetivo garantir a todos existência digna, seguindo os preceitos da justiça social, em conformidade com o artigo 170, VIII da Constituição Federal, que trata do princípio da busca do pleno emprego.

As leis são criadas visando atender aos interesses da sociedade de forma harmônica e justa. A Constituição Federal (1988) atribui grande importância à vida humana, dispondo em seu artigo $5^{\circ}$ que "todos são iguais perante a lei, sem distinção de qualquer natureza, garantindo-se aos brasileiros e aos estrangeiros residentes no País a inviolabilidade do direito à vida, à liberdade, à igualdade, à segurança e à propriedade.” (Brasil, 1988)

Ainda, Leite (2019) afirma que concerne ao Estado assegurar que o indivíduo permaneça vivo, consoante tenha uma vida digna, uma vez que diferente disso estaria contrariando o princípio da dignidade da pessoa humana.

Deste modo, enfatizando a integridade física, visto que é um direito fundamental, acerca dos menores de idade, o Estatuto da Criança e do Adolescente (Lei $n^{\circ}$. 8.069/90), no artigo $7^{\circ}$, declara que "a criança e o adolescente têm direito à 
proteção, à vida e à saúde, mediante a efetivação de políticas sociais públicas que permitam o nascimento e o desenvolvimento sadio e harmonioso em condições dignas de existência".

A essência da Constituição é ser compreendida como lei fundamental e suprema de um Estado, de acordo com Barruffini (2006), ela contém normas referentes à estruturação do Estado, à formação dos poderes públicos, à forma de governo e à aquisição do poder de governar, direitos e deveres dos cidadãos.

A respeito dos princípios constitucionais Dias (2016, p. 74), afirma que

Existem princípios gerais que se aplicam a todos os ramos do direito, assim o princípio da dignidade, da igualdade, da liberdade, bem como os princípios da proibição de retrocesso social e da proteção integral a crianças e adolescentes. Seja em que situações se apresentem, sempre são prevalentes. Os princípios constitucionais representam o fio condutor da hermenêutica jurídica, dirigindo o trabalho do intérprete em consonância com os valores e interesses por eles abrigados.

É evidente que a Constituição de 1988 assegura o direito fundamental à igualdade, conforme consta no artigo $5^{\circ}$, caput. O direito à igualdade é fundamental no Estado Democrático de Direito.

\subsection{Princípios da dignidade da pessoa humana e da isonomia}

Os princípios provocam a criação das normas, tendo como principal funcionalidade o fundamento para a formação e alteração das leis, assim para Dias (2016, p. 46), "no contexto de um Estado Democrático de Direito, em que impera a legalidade material, os princípios servem de parâmetro normativo para aferição da validade de toda e qualquer norma jurídica, ocasionando a inconstitucionalidade de todos os dispositivos que lhes são contrários."

Além disso, a autora declara que a falta de atenção ao princípio resulta a um desrespeito não somente a um princípio fundamental, mas a todo o ordenamento, sendo que para o princípio ser reconhecido, precisa ser subordinante e não subordinado a regras. (Dias, 2016)

Primeiramente, o princípio da dignidade da pessoa humana está declarado na Constituição Federal, em seu artigo $1^{\circ}$, o qual é o precursor do Estado Democrático de Direito, assim

O princípio da dignidade humana não representa apenas um limite à atuação do Estado, mas constitui também um norte para a sua ação positiva. O Estado não tem apenas o dever de abster-se de praticar atos que atentem contra a dignidade humana, mas também deve promover essa dignidade através de condutas ativas, garantindo o mínimo existencial para cada ser humano em seu território. (Dias, 2016, p. 74)

Ainda, a autora afirma que o constituinte sancionou a dignidade da pessoa humana como valor fundamental da ordem constitucional, visto que se faz necessário ter um cuidado com os direitos humanos e com a justiça social. (Dias, 2016)

De outro lado, Barruffini (2006) ensina que o princípio da Isonomia tem o sentido de vedar que a lei ampare situações injustas, além disso, o reconhecimento da igualdade jurídica requisita que as desigualdades sucedem somente da diferença das aptidões pessoais.

$\mathrm{O}$ autor ainda declara que o importante é que o legislador tenha como objetivo estabelecer tratamento desigual para situações desiguais, não podendo, todavia, tratar desigualmente situações que não são desiguais, sob pena de incidir em inconstitucionalidade.

Em virtude da vida, a Constituição protege a integridade física, que deve ser entendida como o absoluto respeito à integridade corporal e psíquica de todo e qualquer ser humano (art. $5^{\circ}$, XLIX). 


\subsection{Dos direitos sociais}

Na Constituição Federal (1988) há um capítulo específico referente aos direitos sociais - Capítulo II, que em seu artigo $6^{\circ}$ indica esses direitos citando: a educação, a saúde, a alimentação, o trabalho, a moradia, o transporte, o lazer, a segurança, a previdência social, a proteção à maternidade e à infância, a assistência aos desamparados, na forma desta Constituição, com o foco em uma sociedade mais igualitária e mais justa.

Os direitos sociais representam uma contribuição positiva por parte do Estado, com um foco na classe menos favorecida da sociedade. Pinho (2002) traz alguns exemplos de direitos sociais: jornada de trabalho de oito horas diárias, salário mínimo, descanso semanal remunerado, férias, aposentadoria, previdência social e licença-gestante. Ainda afirma que, muitos desses direitos só foram promulgados após várias lutas e derramamento de sangue. As primeiras Constituições a inserir em seus textos direitos sociais foram a mexicana de 1917 e a da República Alemã de Weimar em 1919.

Sobre os direitos sociais pontua Barruffini (2006, p. 156),

Os Direitos sociais, como verdadeira dimensão dos direitos fundamentais do homem, são as prestações positivas proporcionadas pelo Estado, direta ou indiretamente, através de enunciados em normas constitucionais, que possibilitam melhores condições de vida aos mais fracos, cujos direitos tendem a realizar a igualização de situações sociais desiguais. Dessarte, são direitos que se ligam ao direito de igualdade; pode-se dizer que são pressupostos do gozo aos direitos individuais, criando condições materiais propícias ao auferimento da igualdade real e que, por via de consequência, possibilita o exercício efetivo da liberdade.

Ademais, a Constituição também objetiva valorizar os direitos sociais, por isso há um Capítulo exclusivo - Dos direitos e garantias fundamentais -, sendo que os demais direitos sociais estão descritos no art. $6^{\circ}$ e, também, em dispositivos do Título VIII, que trata sobre a ordem social, assim

É importante observar que interessa ao trabalhador assegurar tanto o respeito de seus direitos individuais como o de seus direitos sociais, não existindo contradição alguma entre as denominadas gerações de direitos. A primeira Constituição brasileira a incorporar direitos sociais em seu texto foi a de 1934. Até a Carta de 1988, eles estavam inseridos em um capítulo dedicado à ordem econômica e social. (Pinho, 2002, p. 163)

Nesse sentido, para além da proteção dos direitos individuais, nosso ordenamento jurídico assegura, igualmente, a proteção constitucional dos direitos, como forma de preservação de direitos fundamentais, garantindo a existência humana digna e a ascensão da justiça social.

\section{A Maternidade e o Trabalho}

A maternidade é algo transformador e quando se trabalha as mudanças se tornam ainda maiores. Há diversos desafios que afloram com a chegada da maternidade e a mãe necessita conciliar e procurar o equilíbrio entre o trabalho, demais afazeres e a maternidade.

No ambiente de trabalho, muitas mulheres vivenciam momentos de grandes mudanças, o temor de transferência, de serem dispensadas, julgam e analisam antecipadamente, com a certeza de que tudo pode mudar e atrapalhar a carreira. A realidade é que tudo muda, tanto na vida pessoal quanto na vida profissional, e o efeito dessa mudança depende de como é enfrentado esse momento.

Infelizmente, isso se reflete no número de mulheres que pedem demissão após o nascimento de um filho, conforme dados apresentados por Thomas (2020, p. 49): "Os números sobre mulheres que deixam o mercado de trabalho no primeiro ano de vida do bebê são alarmantes. $75 \%$ é o percentual de mulheres que empreendem depois da maternidade segundo dados de pesquisa revelados pela Rede Mulher Empreendedora (RME) 2019”. 
O retorno ao trabalho, após a licença maternidade, é um momento de muitas reflexões, perguntas e até mesmo frustrações. No ambiente de trabalho ainda é crível alcançar os objetivos, por exemplo ser promovida, porém em um ritmo diferente.

E estas dificuldades se prolongam por meses e anos, já que ter um filho é uma responsabilidade constante, Thomas (2020, p.150) declara que " $48 \%$ das mulheres deixam os seus trabalhos até dois anos depois da licença maternidade (conforme resultado de uma pesquisa da Fundação Getulio Vargas (FGV) com 247 mil mulheres, em 2016).”

Há um grande esforço tanto no período gestacional quanto após o nascimento do filho, pois há muitas mudanças, como: o desconforto da gestação, noites mal dormidas, turbilhão de emoções, alterações hormonais que geram oscilações de humor.

Não são poucas as mães que ao retornar da licença maternidade não se sentem seguras, pois o retorno é precoce já que a maioria das empresas segue o período de afastamento previsto na legislação, de apenas 120 dias. Dessa forma, muitas mães optam por deixar o emprego para cuidar de seus filhos, o que dificulta o retorno destas mulheres para o mercado de trabalho.

\subsection{A importância da amamentação exclusiva}

A amamentação por meio do leite materno proporciona um crescimento infantil saudável, devido às propriedades nutricionais que o leite promove à criança, além disso a redução de infecções que afetam o crescimento (por exemplo a diarreia e as doenças respiratórias), conforme afirma,

A falta de amamentação exclusiva entre crianças de 0 a 5 meses de idade e não amamentação entre crianças de 6 a 23 meses de idade estão associadas ao aumento da morbidade e mortalidade por diarreia nos países em desenvolvimento. Estimamos os efeitos protetores conferidos por níveis variáveis de exposição à amamentação contra a incidência de diarreia, prevalência de diarreia, mortalidade por diarreia, mortalidade por todas as causas e hospitalização por doença diarreica. (Lamberti et al., 2011)

Assim, também, amplifica o quociente de inteligência infantil, ajudando a diminuir a possibilidade de a criança desenvolver sobrepeso, diabetes e, ainda, proteção contra infecções infantis e má oclusão. (Victora et al., 2016).

Ainda sobre os benefícios que a amamentação afirma que,

(...) para as mulheres que amamentam, a amamentação deu proteção contra o câncer de mama e melhorou o espaçamento dos nascimentos, e também pode proteger contra câncer de ovário e diabetes tipo 2. A ampliação do aleitamento materno a um nível quase universal poderia prevenir 823.000 mortes anuais em crianças menores de 5 anos e 20.000 mortes anuais por câncer de mama. Descobertas epidemiológicas e biológicas recentes durante a última década expandem os benefícios conhecidos da amamentação para mulheres e crianças, sejam elas ricas ou pobres." (Victora et al., 2016)

Além disso, incentivando e dando condições para a amamentação exclusiva é mais econômico para a família e para o

Estado, do que substituir o leite materno por outro leite ou fórmula artificial na alimentação do bebê, assim

São raros os estudos que comparam o custo da alimentação complementar da mãe com o uso de substitutos do leite materno. Visando uma análise comparativa dos dados obtidos no Brasil com outros trabalhos, e considerando que o momento de sua obtenção dos mesmos era diferente, procurou-se fazer essa análise tomando como referência os valores anuais em dólares. Observou-se que os resultados deste estudo foram similares aos observados na Costa do Marfim e na França ainda que em épocas diferentes. (Araujo et al., 2004)

Seguindo orientação da OMS (2009), é recomendado alimentar os bebês com leite materno por, no mínimo, seis meses. A partir deste período já poderão ser introduzidos outros tipos de alimentos. Com um período de 120 dias de licença maternidade, verifica-se que muitas mães enfrentam dificuldades para amamentar seus filhos, já que devem retornar ao trabalho. 
Além disso, esse aumento do período da licença é essencial não somente para o aleitamento, pois há mães que não amamentarão, mas precisam permanecer com seus filhos por um período maior que apenas 120 dias para fortalecer o vínculo afetivo, pois

Para as crianças se desenvolverem bem emocional e cognitivamente necessitam de amor materno. Essa ligação criançamãe precisa, segundo especialistas, de importante continuidade de cuidado afetivo para ser eficaz. Não necessariamente esse amor materno precisa ser da mulher que o gerou, mas podendo ser também de alguém que vai desempenhar a função cuidadora, como por exemplo, a mãe adotiva. (Revrene, 2014, p. 250)

Levando este fato em consideração, a análise proposta é a da viabilidade jurídica da ampliação da licença maternidade.

Em 2008, foi criado pelo Governo Federal o Programa Empresa Cidadã, regulamentado pela Lei 11.770/2008, que promove a concessão de incentivos às empresas que aderirem, sendo seu foco a extensão da licença maternidade que pode ser prorrogada por 60 dias. Porém, a adesão é facultativa, sendo necessário que a pessoa jurídica contrate o programa, de modo que haverá benefícios com deduções fiscais.

Obviamente, nem todas as empresas optam por esse programa, sendo assim apenas pequena parcela das mães que trabalham têm direito ao benefício desse prolongamento do período de licença maternidade de 60 dias, implicando em tratamento desigual entre as trabalhadoras.

\subsection{Programa empresa cidadã}

No decorrer da história ocorreram mudanças no direito social para as mulheres, a preservação e manutenção de seu trabalho, a conquista da concessão da licença-maternidade, entre outros.

A Lei n ${ }^{\circ} 11.770 / 2008$ permitiu a prorrogação do período de licença-maternidade para as mães que laboram em empresas tributadas pelo regime de Imposto de Renda Pessoa Jurídica (IRPJ) sobre lucro real, conforme afirma Barros (2019), há uma desigualdade de tratamento em relação às que atuam em empresas com outro tipo de tributação.

No artigo $7^{\circ}$ da Constituição Federal constam os principais direitos dos "trabalhadores, urbanos e rurais, além de outros que visem à melhoria de sua condição social". Especificamente sobre o tema,

Há muito se clama por maior atenção à maternidade, tanto do ponto de vista do conforto e bem estar da mulher gestante empregada, quanto, e principalmente, das necessidades do aleitamento materno por maior período, assim como da maior interação e sinergia entre mãe e filho, durante os cruciais primeiros momentos da vida. (Barros, 2019, [sp.]).

Em 9 de setembro de 2008 foi promulgada a Lei no 11.770 com o objetivo de criar o Programa Empresa Cidadã com a prerrogativa de incentivos fiscais. Porém, a considerar os requisitos autorizadores da participação da empresa no programa, qual seja, a submissão da empresa à tributação sobre o lucro real, verifica-se dessa forma, se estabelece uma desigualdade de tratamento em relação às mulheres gestantes, dependendo do local onde trabalham.

Com a alteração da Lei $\mathrm{n}^{\circ}$ 8.212/1991 por meio da Lei $\mathrm{n}^{\circ}$ 11.770/2008 ficou autorizada a prorrogação da licençamaternidade concedendo benefícios para as empresas que participam do "Programa Empresa Cidadã", isto é, a concessão de incentivos fiscais, sendo os pagamentos efetuados às licenciadas com a possibilidade de serem totalmente deduzidos do Imposto de Renda com base no lucro real com a condição de que as empresas estendam o período da licença maternidade por mais 60 dias, quando solicitado pelas gestantes ou adotantes.

A lei responsável pela criação do "Programa Empresa Cidadã" beneficia a empresa que declara Imposto de Renda de pessoa jurídica de lucro real, não enquadrando as outras formas de levantamento para o IRPJ (Imposto de Renda Pessoa Jurídica), tais como SIMPLES (Sistema Integrado de Pagamentos de Impostos) e Contribuições das Microempresas e Empresas de Pequeno Porte, Lucro Presumido e Lucro Arbitrado. 
Essas informações estão expostas no artigo $5^{\circ}$ da Lei $n^{\circ}$ 11.770/2008: “A pessoa jurídica tributada com base no lucro real poderá deduzir do imposto devido, em cada período de apuração, o total da remuneração integral da empregada e do empregado pago nos dias de prorrogação de sua licença-maternidade e de sua licença-paternidade, vedada a dedução como despesa operacional,” assim,

Muitas empresas brasileiras que gostariam de se cadastrar no programa Empresa Cidadã (para beneficiar a mãe por um prazo de mais 60 dias, totalizando 180 dias de licença-maternidade), não o podem porque a maior parte adere ao imposto sobre o Lucro Simples ou outras formas de contribuição, que são mais flexíveis e custam menos para o empreendedor. Apenas as empresas que declaram os impostos sobre o Lucro Real podem se cadastrar no programa e estima-se que são pouco menos de $8 \%$ do total das empresas ativas no país as que declaram Imposto de Renda sobre o Lucro Real. (Meireles; Freguglia; Corseul, 2019, p. 4)

Em síntese, fica claro que os benefícios são voltados apenas a uma parcela das empresas ativas em nosso país, visto que não há obrigatoriedade e assim, parte dos administradores optarem pela adesão.

\section{Legislação Internacional}

Comparando a licença maternidade do Brasil com a prevista em outros países, tais como Canadá, França, Moçambique e Portugal, é possível perceber que o Canadá é o país que melhor ampara a mulher, apresentando 355 dias de licença maternidade.

As políticas adotadas pelo Canadá, são projetadas para auxiliar os pais a permanecerem em casa com seus bebês, proporcionando aos pais proteção jurídica profissional e apoio financeiro quando eles se despedem do trabalho. A maioria dos canadenses goza de boa saúde para excelente saúde física e mental. Devido, em parte, aos esforços de saúde pública. (Brandão, et al., 2020 p. 71)

Já a legislação de Moçambique, de acordo com os autores supracitados é a de menor valorização da mulher trabalhadora, pois o período de licença maternidade determinado é de 60 a 90 dias, apesar de garantir o valor integral de seu salário, institui uma desestabilidade quando limita esse período de envolvimento materno-infantil, conforme demonstra na tabela abaixo:

Tabela 1 - Legislação vigente acerca da licença-maternidade.

\begin{tabular}{|c|c|c|}
\hline País & Legislação trabalhista & Período da licença \\
\hline Brasil & Lei $\mathrm{n}^{\circ} 5.452$ de $1^{\circ}$ de maio de 1943 . Art. 392 & $120 / 180$ dias. \\
\hline Canadá & Código do trabalho: Art. 205, 22 de junho de 2017 & 355 dias. \\
\hline França & Código do trabalho: Art. L.1225-17. & 112/322 dias. \\
\hline Moçambique & Código do trabalho: Lei no 23/2007. Art. 10 & $60 / 90$ dias. \\
\hline Portugal & Código do trabalho: Lei nº/2009. Art. 39-42 & $120 / 150$ dias. \\
\hline
\end{tabular}

Fonte: Universidade Estadual do Ceará - UECE.

Como pode-se notar, há países que disponibilizam em suas leis um período de licença maternidade maior, atribuindo assim um benefício maior e melhor, se comparado à legislação brasileira. 


\section{Considerações Finais}

Do estudo, há que se concluir que os direitos e garantias fundamentais dos indivíduos devem ser respeitados, sem distinção, sendo imprescindível a proteção desses direitos na busca de uma sociedade mais igualitária e justa. Os direitos fundamentais, tanto os individuais como os sociais, são garantidos pela Constituição da República e devem ser resguardados e efetivados. Dentre os direitos sociais, o direito ao trabalho merece relevância, pois assegura direito basilar da vida humana.

No que pertine aos direitos das mulheres ressaltou-se a conquista do direito à licença maternidade e à amamentação frisando sua importância, bem como as necessidades físicas e emocionais relacionadas a este período e seus efeitos na relação de trabalho e na vida pessoal da empregada e seu filho.

Ponderando a legislação interna e estrangeira verificou-se a insuficiência do período de licença maternidade previsto atualmente em contraposição à recomendação da OMS para o aleitamento materno. Não obstante a vigência da Lei no 11.770 que criou o Programa Empresa Cidadã verifica-se que a política adotada não se mostra efetiva, pois a ampliação da licença maternidade acaba por beneficiar apenas as mulheres que laboram nas empresas que aderirem ao programa, ferindo o princípio da isonomia.

Por fim, fica evidente que o benefício da licença maternidade deve ser reavaliado, visto que há a necessidade de sua ampliação em respeito aos princípios constitucionais de modo que, atenda às necessidades da mãe e do filho.

\section{Agradecimentos}

Em especial à orientadora Raquel Lauriano Rodrigues Fink, a qual não mediu esforços para a publicação desse artigo.

\section{Referências}

Araújo, M.F.M., Fiaco, A. D., Pimentel, L. S. \& Schmitz, B.A.S. Custo e economia da prática do aleitamento materno para a família. https://www.scielo.br/scielo.php?script=sci_arttext\&pid=S1519-38292004000200003\&lng=pt\&tlng=pt

Barros, G. A. (2014). A Lei e a Prorrogação da Licença-Maternidade. Baraúna.

Barruffini, J. C. T. (2005). Direito constitucional. Saraiva.

Brasil. (1943). Decreto-lei no 5.452, de $1^{\circ}$ de maio de 1943. Aprova a Consolidação das Leis do Trabalho. http://www.planalto.gov.br/ccivil_03/decretolei/del5452.htm.

Brasil. (1988). Constituição da República Federativa do Brasil: promulgada em 5 de outubro de 1988. http://www.planalto.gov.br/ccivil_03/constituicao/constituicao.htm.

Brasil. (1990). Lei $n^{o}$ 8.069, de 13 de julho de 1990. Dispõe sobre o Estatuto da Criança e do Adolescente e dá outras providências. http://www.planalto.gov.br/ccivil_03/leis/18069.htm.

Brasil. (2008). Lei $n^{\circ} 11.770$, de 9 de setembro de 2008. Cria o Programa Empresa Cidadã, destinado à prorrogação da licença-maternidade mediante concessão de incentivo fiscal, e altera a Lei no 8.212, de 24 de julho de 1991. http://www.planalto.gov.br/ccivil_03/_ato2007-2010/2008/lei/111770.htm.

Brasil. (2009). Ministério da Saúde. Secretaria de Atenção à Saúde. Departamento de Atenção Básica. Saúde da criança: Nutrição infantil: Aleitamento Materno e Alimentação Complementar. Editora do Ministério da Saúde.

Canotilho, J. J. G. (2003). Direito Constitucional e Teoria da Constituição. Almedina.

Dias, M. B. (2016). Manual de Direito das Famílias. Revista dos Tribunais Ltda.

Figueredo, E. (2009). Monografia: A Estabilidade Provisória Das Empregadas Gestantes Nas Relações De Emprego.

Lamberti, L.M., Fischer Walker, C.L., Noiman, A. Victora, C. \& Black, R E. (2011) Amamentação e o risco de morbimortalidade por diarreia. BMC Public Health. https://doi.org/10.1186/1471-2458-11-S3-S15.

Martins, S. P. (2019). Direito do trabalho. Saraiva Educação.

Meireles, D. C., Freguglia, R. S. \& Corseuil, C. H. L. (2017). Programa Empresa Cidadã: Os impactos do aumento da licença-maternidade sobre os trabalhadores. https://www.anpec.org.br/encontro/2017/submissao/files_I/i12-fbcbde83b492e491ea58cd18fa34b370.docx.

Nascimento, A. M. (2010). Curso de Direito do Trabalho: história e teoria geral do direito do trabalho: relações individuais e coletivas do trabalho. Saraiva. 
Research, Society and Development, v. 10, n. 6, e25610615697, 2021

(CC BY 4.0) | ISSN 2525-3409 | DOI: http://dx.doi.org/10.33448/rsd-v10i6.15697

Pinho, R. C. R. (2002). Teoria Geral da Constituição e Direitos Fundamentais. Saraiva.

Thomas, S. (2020). Os impactos reais da Maternidade no Trabalho. Sumaia Thomas. E-Book. https://ler.amazon.com.br/?asin=B083S9DMYM.

Tribunal de Justiça do Distrito Federal e dos Territórios. Grupo Vínculo - Apoio voluntário especializado para cuidados com a vida. Vantagens da amamentação para o desenvolvimento da face. https://www.tjdft.jus.br/informacoes/programas-projetos-e-acoes/pro-vida/dicas-de-saude/pilulas-de-saude/vantagens-daamamentacao-para-o-desenvolvimento-da

face\#: :text=\%22\%C3\%89\%20importante\%20para\%20o\%20beb\%C3\%AA,afetivo\%20entre\%20m\%C3\%A3e\%20e\%20filho\%2C. Acesso em: 13 ago. 2020.

Universidade Estadual do Ceará - UECE. Legislação trabalhista internacional e sua interface com a saúde materno-infantil. http://biblioteca.cofen.gov.br/wpcontent/uploads/2020/07/LegislacaoTrabalhistaSaudeMaternoInfantil-1.pdf.

Victora, C. G., Bahl, R., Barros, A. J., França, G. V., Horton, S., Krasevec, J., Murch, S., Sankar, M. J., Walker, N. \& Rollins, N.C. (2016). Breastfeeding in the 21st century: epidemiology, mechanisms, and lifelong effect. Lancet. https://pubmed.ncbi.nlm.nih.gov/26869575/ 